\title{
PELATIHAN PENYUSUNAN PERANGKAT PEMBELAJARAN BERBASIS TIK BAGI GURU AKUNTANSI SMK
}

\author{
Dudung Ma'ruf Nuris*1, Suparti ${ }^{2}$, Sulastri $^{3}$ \\ ${ }^{1,2,3}$ Program Studi Pendidikan Akuntansi, Fakultas Ekonomi, Universitas Negeri Malang \\ Jalan Semarang No. 5 Malang \\ E-mail: dudung.ma'ruf.fe@um.ac.id
}

\begin{abstract}
The purpose of holding Community Partnership Program activities in Accounting teachers in SMK are: (1) Increasing knowledge of Vocational High School in Blitar for Accounting teachers about interactive learning tools for accounting learning which can be made online or offline; (2) Improving the skills of accounting teachers in Vocational high School on how to develop interactive learning tools for accounting learning. Community service is done by the method of training and mentoring for vocational high school accounting teachers to arrange learning tools both online and offline. Training on the preparation of ICT-based learning tools was attended by vocational high school teachers majoring in accounting in Blitar city. Community service activities were held in SMKN 2 Blitar hall with 3 lecturers, 1 education staff and 2 students. Form of activities carried out in the form of training and mentoring. The output of this activity is the teacher can arrange learning tools both offline and online. The material submitted to the training is offline-based by providing material exposure on lesson plan devices, Syllabus, and other devices according to the revised K-13 curriculum. Training activities for the preparation of ICT-based learning tools are planned for every school in Blitar city with an accounting expertise program
\end{abstract}

Keywords - Learning Portofolio, Information Technology, Accounting Teacher

\section{Abstrak}

Tujuan diadakannya kegiatan Program Kemitraan Masyarakat pada guru Akuntansi di SMK adalah: (1) Meningkatkan pengetahuan guru Akuntansi SMK Kota Blitar tentang perangkat pembelajaran interaktif untuk pembelajaran akuntansi yang dapat dibuat secara online maupun offline; (2) Meningkatkan keterampilan guru akuntansi di SMK dan SMA Kota Blitar tentang cara menyusun perangkat pembelajaran interaktif untuk pembelajaran akuntansi. Pengabdian masyarakat ini dilakukan dengan metode pelatihan dan pendampingan bagi guru-guru akuntansi SMK untuk menyusun perangkat pembelajaran baik secara online maupun offline. Pelatihan penyusunan perangkat pembelajaran berbasis TIK dihadiri oleh guru-guru SMK jurusan akuntansi se-kota Blitar. Kegiatan pengabdian masyarakat diselenggarakan di aula SMKN 2 Blitar dengan melibatkan 3 orang dosen, 1 tendik dan 2 mahasiswa. Bentuk kegiatan yang dilaksanakan berupa pelatihan dan pendampingan. Output dari kegiatan ini yaitu guru dapat menyusun perangkat pembelajran baik secara offline maupun online. Materi yang disampaikan pada pelatihan tersebut berbasis offline dengan cara memberikan pemaparan materi tentang perangkat RPP, Silabus, dan perangkat lain sesuai kurikulum K-13 yang telah direvisi. Kegiatan pelatihan penyusunan perangkat pembelajaran berbasis TIK disaranklan dilakukan di setiap sekolah di kota Blitar yang mempunyai program keahlian akuntansi

Kata Kunci-Perangkat Pembelajaran, Teknologi Informasi, Guru Akuntansi

\section{PENDAHULUAN}

Perkembangan teknologi terutama TIK, telah mempengaruhi seluruh aspek kehidupan tidak terkecuali di bidang pendidikan. Pengembangan dan pemanfaatan media pembelajaran berbasis TIK baik yang bersifat offline maupun online, bisa dimanfaatkan sebagai bahan masukan bagi pihak-pihak yang berminat terutama pihak pendidik. Maka dari itu teknologi informasi dan komunikasi dapat memudahkan kita untuk belajar dan mendapatkan informasi yang kita butuhkan 
dari mana saja, kapan saja, dan dari siapa saja. Khairi (2015) Pembelajaran berbasis TIK secara esensi merupakan pembelajaran yang tidak hanya mencakup kemampuan membelajarkan peserta didik, tetapi juga kemampuan guru dalam mengelola informasi yang akan disampaikannya dan mengorganisasi lingkungan pembelajaran yang dapat memberikan fasilitas bagi peserta didik untuk lebih mudah untuk melakukan aktivitas belajar. Untuk dapat memanfaatkan TIK dalam memperbaiki mutu pembelajaran, ada tiga hal yang harus diwujudkan yaitu: (1) siswa dan guru harus memiliki akses kepada teknologi digital dan internet dalam kelas, sekolah, dan lembaga pendidikan guru, (2) harus tersedia materi yang berkualitas, bermakna, dan dukungan cultural bagi siswa dan guru, dan (3) guru harus memiliki pengetahuan dan ketrampilan dalam menggunakan alat-alat dan sumber-sumber digital untuk membantu siswa agar mencapai standar akademik

Aktivitas-aktivitas yang dilakukan dalam pembelajaran hendaknya dapat memberikan kesempatan seluas-luasnya kepada siswa untuk melakukan aktivitas tingkat tinggi sehingga kemampuan tingkat tinggi dapat dioptimalkan. Aktivitas-aktivitas tersebut dapat dirancang melalui suatu perangkat pembelajaran seperti silabus, RPP, bahan ajar, dan media pembelajaran yang sesuai. Anggrahini (2014) agar tujuan pembelajaran mencapai sasaran dengan baik perlu adanya pemilihan pendekatan atau strategi pembelajaran yang sesuai, juga perlu adanya pengembangan perangkat pembelajaran yang sesuai pula dengan strategi pembelajaran yang digunakan. Salah satu perangkat yang dikembangkan yaitu bahan ajar. Bahan ajar adalah segala bentuk bahan yang digunakan untuk membantu guru/instruktur dalam melaksanakan kegiatan belajar mengajar. Bahan yang dimaksud bisa berupa bahan tertulis maupun bahan tidak tertulis. Pemanfaatan bahan ajar harus dapat dioptimalkan sebagai sarana untuk mengembangkan kemampuan tingkat tinggi siswa sekaligus memberikan tantangan dan kesempatan seluas-luasnya bagi siswa melakukan berbagai aktifitas tingkat tinggi. Salah satu jenis bahan ajar adalah buku teks. Buku teks yang ada kebanyakan hanya berisi informasi materi dan soal-soal saja sehingga belum menstimulus kemampuan tingkat tinggi.

Berdasarkan pemaparan dari salah satu pengurus Musyawarah Guru Mata Pelajaran di Kota Blitar diketahui bahwa mayoritas guru-guru akuntansi SMK di Kota Blitar sudah mampu membuat perangkat pembelajaran secara offline akan tetapi belum mampu mengembangkan secara luas sesuai dengan perkembangan terkini. Permasalahan tersebut banyak terjadi di berbagai daerah, seperti yang diungkapkan oleh Mardiah (2013) yang menyatakan bahwa guru kurang memahami prinsip penyusunan silabus dan RPP. Perangkat pembelajaran yang dimaksud berupa pengembangan RPP. Menurut Chusni (2014) Pentingnya menyusun RPP yang disusun secara profesional, sistematis, dan berdaya guna, dapat meningkatkan kemampuan pendidik untuk melihat, mengamati, menganalisis, dan memprediksi program pembelajaran sebagai kerangka kerja yang logis dan terencana. Masalah lain muncul saat guru-guru akuntansi di SMK belum mampu menyusun perangkat pembelajaran secara online yang mana merupakan tuntutan dari perkembangan teknologi informasi dan komunikasi. Oleh karena itu diperlukan pelatihan penyusunan perangkat pembelajaran berbasis TIK bagi guru akuntansi SMK. Syahbana (2012) Prototype perangkat pembelajaran yang dikembangkan efektif meningkatkan aktivitas belajar siswa dan memiliki potential effect terhadap kemampuan berpikir kritis siswa. Penyusunan perangkat pembelajaran tersebut diharapkan dapat meningkatkan kualitas pembelajaran di kelas dan menciptakan keaktifan siswa sehingga tujuan pembelajaran yang ingin dicapai dapat terealisasi sesuai rencana yang disusun.

\section{METODE}

Pengabdian masyarakat ini dilakukan dengan metode pelatihan dan pendampingan bagi guru-guru akuntansi SMK untuk menyusun perangkat pembelajaran baik secara online maupun offline. Penyusunan perangkat secara online menggunakan software I-SPRING. Software tersebut diinstal secara offline namun penggunaannya dapat dilakukan secara online saat dihubungkan dengan internet. Perangkat pembelajaran offline yang dimaksud disini adalah menyusun Rencana Pelaksanaan Pembelajaran (RPP) dan Silabus. Pelatihan dan pendampingan dilakukan oleh dosen dari jurusan akuntansi yang terdiri dari Dr. Suparti, M.P, Dudung Ma'ruf Nuris, S.Pd., M.Pd., dan Sulastri, S.Pd., M.SA dan dibantu dengan tenaga kependidikan dan 2 mahasiswa dari Universitas Negeri Malang. 
DINAMISIA - Jurnal Pengabdian Kepada Masyarakat Vol. 2, No. 2 Desember 2018, Hal. 256-260

Rancangan kegiatan PKM Kelompok guru Akuntansi SMK di Kota Blitar dapat dilihat pada Gambar 1 berikut ini.

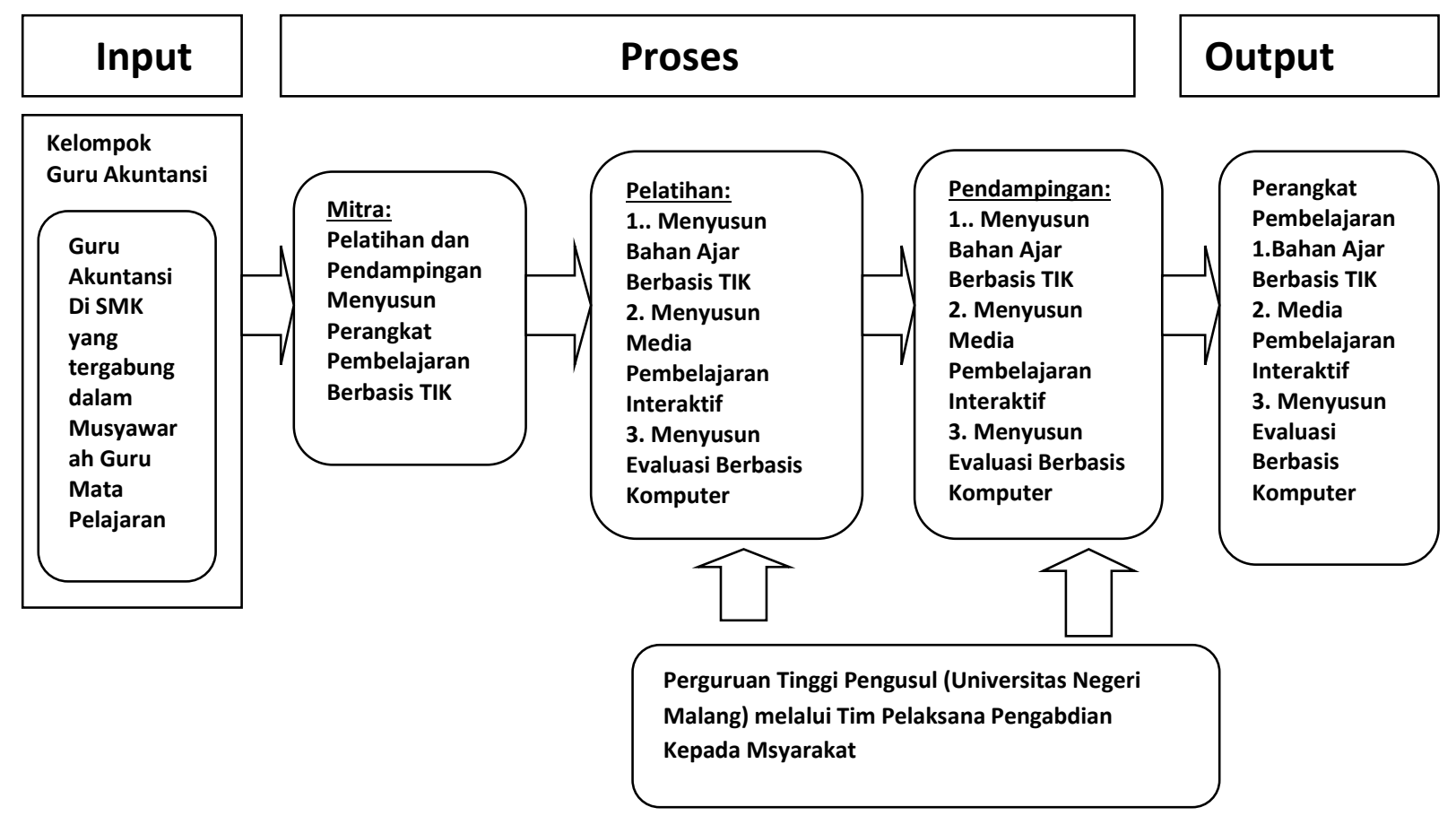

Gambar 1. Rancangan PKM Kelompok Guru Akuntansi di SMK

Pada gambar tersebut diketahui bahwa sasaran utama dalam kegiatan ini adalah guru-guru akuntansi di seluruh wilayah Blitar kota yang tergabung dalam Musyawarah Guru Mata pelajaran,

\section{HASIL DAN PEMBAHASAN}

Pelatihan penyusunan perangkat pembelajaran berbasis TIK dihadiri oleh guru-guru SMK jurusan akuntansi se-kota Blitar. Kegiatan pengabdian masyarakat diselenggarakan di aula SMKN 2 Blitar dengan melibatkan 3 orang dosen, 1 tendik dan 2 mahasiswa. Bentuk kegiatan yang dilaksanakan berupa pelatihan dan pendampingan. Dosen yang terlibat yaitu Bapak Dudung Ma'ruf Nuris, Ibu Suparti, dan Ibu Sulastri serta dihadiri oleh Kepala Sekolah SMKN 2 Blitar berserta para peserta dari berbagai SMK di Kota Blitar. Materi pertama disampaikan oleh Ibu Dr. Suparti, M.P yang membahas tentang penyusunan perangkat pembelajaran secara manual atau offline. Yuniarti (2014) perangkat pembelajaran dikatakan baik apabila valid, efektif, dan praktis.

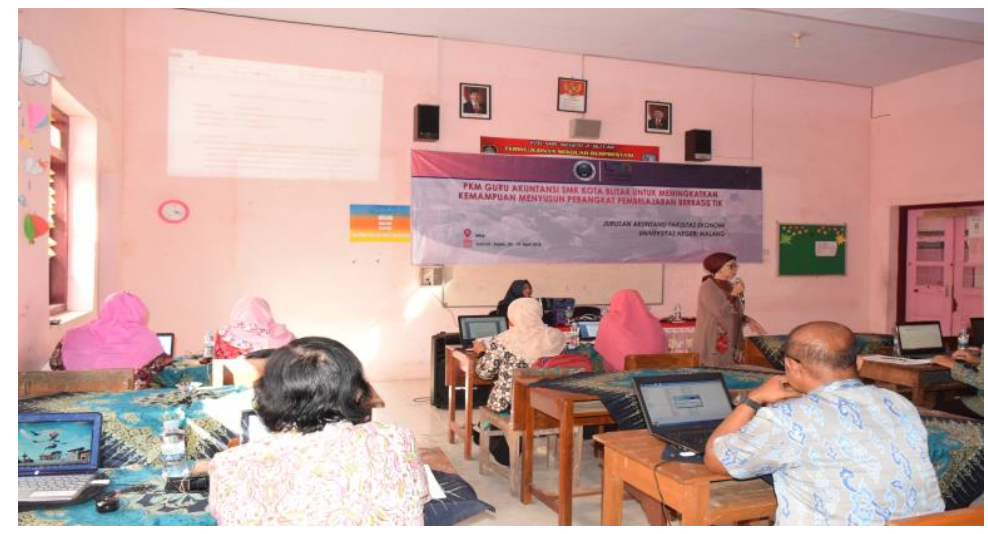

Gambar 2. Pemaparan pemateri pertama

Penyusunan perangkat pembelajaran secara offline diharapkan dapat menambah wawasan para guru untuk meningkatkan profesionalitas dan kemampuan pedagogik para guru. Diharapkan 
dengan peningkatan tersebut dapat menciptakan proses pembelajaran yang baik di kelas. Nizarwati (2009) prototype perangkat pembelajaran yang dikembangkan efektif untuk meningkatkan aktivitas belajar siswa. Dari hasil yang didapatkan menunjukkan guru-guru akuntansi SMK di kota Blitar telah mampu menyusun perangkat pembelajaran offline dengan baik. Hal ini dikarenakan, para guru telah mempunyai pengalaman dalam menyusun Silabus maupun RPP yang menjadi pekerjaan mereka sehari-hari. Hal ini sejalan dengan yang dikemukakan Susetya (2017) silabus dan RPP yang dibuat guru bersifat original dan mampu menyusun RPP sesuai dengan rencana pembelajaran yang dibuat.

Materi kedua disampaikan oleh Bapak Dudung Ma'ruf Nuris, S.Pd., M.Pd yang menyampaikan tentang penyusunan perangkat pembelajaran secara online dengan menggunakan software I-SPRING, dimana peserta sangat antusias didalam mengikuti materi tersebut.

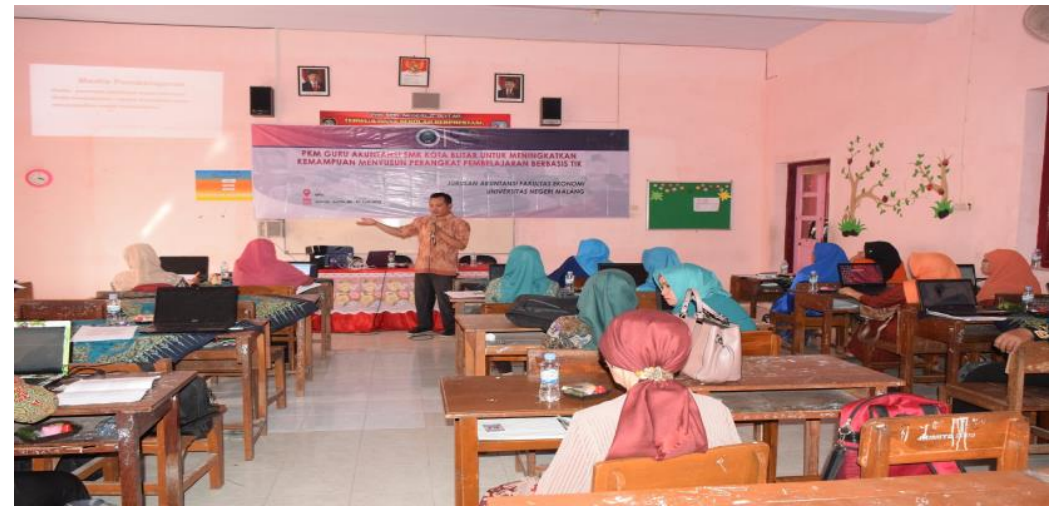

Gambar 3. Pemaparan Pemateri 3

Perangkat pembelajaran berbasis online sangat diperlukan di era revolusi industri 4.0 sekarang ini, yang ditandai dengan penggunaan teknologi informasi dan komunikasi di segala bidang termasuk di bidang pendidikan. Penggunaan perangkat pembelajaran berbasis online dapat menciptakan kepraktisan dalam proses belajar mengajar, sebagaimana hasil penelitian yang disampaikan Wulandari (2014) yang menyatakan bahwa perangkat pembelajaran yang praktis dapat digunakan guru untuk mengelola pembelajaran secara baik. Perangkat pembelajaran yang berbasis online ini diharapkan tidak hanya dinikmati oleh guru di satu wilayah namun dapat dinikmati oleh guru di berbagai daerah di Indonesia melalui fasilitas penyebaran via internet. Santi (2015) Tahap terakhir pada proses pengembangan perangkat pembelajaran adalah tahap penyebaran. Dari pernyataan tersebut maka dapat diketahui bahwa diseminasi ilmu pengetahuan di era industri 4.0 sangatlah penting sebagai sarana meningkatkan profesionalitas seorang guru dan diharapkan dapat merata di seluruh wilayah Indonesia.

\section{KESIMPULAN}

Adapun kesimpulan dari laporan kemajuan pengabdian masyarakat ini adalah

1. Pelatihan penyusunan perangkat pembelajaran berbasis TIK dihadiri oleh guru-guru SMK jurusan akuntansi se-kota Blitar

2. Pemateri pelatihan penyusunan perangkat pembelajaran berbasis TIK yaitu Ibu Dr. Suparti, M.P, Ibu Sulastri, S.Pd., M.SA, dan Bapak Dudung Ma'ruf Nuris, S.Pd., M.Pd dari jurusan akuntansi Fakultas Ekonomi Universitas Negeri Malang.

3. Materi yang disampaikan pada pelatihan tersebut berbasis offline dengan cara memberikan pemaparan materi tentang perangkat RPP, Silabus, dan perangkat lain sesuai kurikulum K-13 yang telah direvisi.

4. Materi lain berupa penyusunan perangkat berbasis online dengan menggunakan software ISPRING yang dapat diunduh secara gratis di www.google.co.id

\section{SARAN}


Berdasarkan kesimpulan tersebut, maka saran yang diajukan dari kegiatan pengabdian kepada masyarakat ini yaitu. (1) Pelatihan penyusunan perangkat pembelajaran berbasis TIK diharapkan dapat diterapkan di semua jenjang pendidikan, baik bagi guru SD, SMP, dan SMA, (2) Kegiatan pengabdian masyarakat hendaknya tidak hanya dilakukan di wilayah Jawa Timur namun dapat dilakukan di daerah lain di Indonesia yang sekiranya sangat membutuhkan.

\section{UCAPAN TERIMA KASIH}

Penulis mengucapkan terima kasih kepada Rektor Universitas Negeri Malang dan Ketua Lembaga Penelitian dan Pengabdian Kepada Masyarakat UM yang telah memberikan bantuan dana dalam penyelenggaraan pengabdian masyarakat ini melalui dana PNBP UM serta mengucapkan terima kasih kepada pimpinan Fakultas Ekonomi UM, panitia dan peserta sehingga acara ini dapat terlaksana dengan baik dan lancar.

\section{DAFTAR PUSTAKA}

[1] Anggrahini dkk. 2014. Pengembangan Perangkat Pembelajaran Matematika Dengan Student Active Learning Berbantuan Media Visual Math Pada Pokok Bahasan Peluang Kelas XI IPA SMA Negeri 2 Purwokerto. Jurnal Elektronik Pembelajaran Matematika Vol. 2 No. 5 Hal. 5045012 Juli 2014.

[2] Chusni, Muhammad Minan. 2017. Peningkatan Kemampuan Menyusun Rencana Pelaksanaan Pembelajaran (RPP) Berbasis Saintifik Bagi Calon Guru Fisika

[3] Khairi, Ashabul. 2015. Kemampuan Pembelajaran Berbasis TIK Pada Guru SMP di Kota Padang Dalam Menyambut Implementasi Kurikulum 2013. Jurnal IPTEKS Terapan Vol. 08 No. 042015.

[4] Mardiah, Radiatan dkk. 2013. Pengembangan Perangkat pembelajaran Untuk Peningkatan Kompetensi Ujian Nasional di Kabupaten Muaro Jambi, Tanjung Jabung Barat dan Tanjung Jabung Timur Provinsi Jambi. Jurnal Pengabdian Pada Masyarakat No. 55 Tahun 2013.

[5] Nizarwati dkk. 2009. Pengembangan Perangkat Pembelajaran Berorientasi Konstruktivisme Untuk Mengajarkan Konsep Perbandingan Trigonometri Siswa Kelas X SMA. Jurnal Pendidikan Matematika Vol. 3 No. 2 Desember 2009.

[6] Santi, Dewi. 2015. Pengembangan Perangkat Pembelajaran Matematika Realistik Pada Pokok Bahasan Lingkaran Kelas VIII SMP. Jurnal Kadikma Vol. 6 No. 1 hal 85-94 April 2015.

[7] Susetya, Beny. 2017. Meningkatkan Kemampuan Guru Dalam Menyusun Silabus dan RPP Melalui Supervisi Akademik Di SDN Gambiran Yogyakarta Tahun 2016. Jurnal Taman Cendekia Vol. 01 No. 02 Desember 2017.

[8] Syahbana, Ali. 2012. Pengembangan Perangkat Pembelajaran Berbasis Kontekstual Untuk Mengukur Kemampuan Berpikir Kritis Matematis Siswa SMP. Jurnal Edumatica Vol. 02 No. 02 Oktober 2012.

[9] Wulandari, Raifi dkk. 2014. Pengembangan Perangkat Pembelajaran Berbasis Pembelajaran Matematika Realistik Pokok Bahasan Kubus dan Balok. Jurnal Pancaran Vol. 3 No. 1 Februari 2014.

[10] Yuniarti, Titik dkk. 2014. Pengembangan Perangkat Pembelajaran Berbasis Masalah (Problem Based Learning) Dengan Pendekatan Ilmiah (Scientific Approach) Pada Materi Segitiga Kelas VII SMP se-Kabupaten Karanganyar. Jurnal Elektronik Pembelajaran Matematika Vol. 2 No. 9 hal 911-921 November 2014. 